\title{
Linear Free Energy Relationship Correlations for Enthalpies of Solvation of Organic Solutes into Room-Temperature Ionic Liquids Based on the Abraham Model with Ion-Specific Equation Coefficients
}

\author{
Laura M. Sprunger, ${ }^{\dagger}$ Sai S. Achi, ${ }^{\dagger}$ William E. Acree, Jr., ${ }^{* \dagger}$ and Michael H. Abraham ${ }^{*}$ \\ Department of Chemistry, 1155 Union Circle Drive Number 305070, University of North Texas, \\ Denton, Texas 76203-5017, and Department of Chemistry, University College London, 20 Gordon Street, \\ London WC1H OAJ, U.K.
}

\begin{abstract}
Mathematical correlations have been developed for describing the enthalpy of solvation of organic solutes into room-temperature ionic liquids (RTILs) based on the Abraham general solvation model with ion-specific equation coefficients. The derived correlations contain six cation-specific and six anion-specific equation coefficients that were determined through regression analyses. The derived equations correlated the observed enthalpies of solvation data to within a standard deviation of about $1.7 \mathrm{~kJ} / \mathrm{mol}$. The nine sets of cationspecific and eight sets of anion-specific equation coefficients that have been calculated can be combined to yield equations capable of predicting the enthalpies of solvation of organic solutes and gases in 72 different RTILs.
\end{abstract}

\section{Introduction}

Room-temperature ionic liquids (RTILs) have generated considerable interest in recent years because of their unique physical and chemical properties. New generation RTILs have become an increasingly popular solvent choice for the manufacture of nanomaterials and new pharmaceutical drug molecules, as stationary-phase liquids for gas chromatographic separations, as gas absorption agents, and as extraction solvent systems for the removal of nitrogen and sulfur components from diesel fuels and petroleum crude oils. As representative examples, Xie and co-workers ${ }^{1}$ reported that up to $50 \%$ of the neutral nitrogen compounds in a straight-run diesel feed could be removed in a single extraction step using either 1-methyl3-butylimidazoium chloride $\left[(\mathrm{MBIm})^{+} \mathrm{Cl}^{-}\right]$or 1-octylpyridinium chloride $\left[(\mathrm{OPy})^{+} \mathrm{Cl}^{-}\right]$, and a RTIL-to-feed ratio of $1 / 10$ by mass. Sulfur compound reduction though was found to be less than $5 \%$ with $\left[(\mathrm{MBIm})^{+} \mathrm{Cl}^{-}\right]$or $\left[(\mathrm{OPy})^{+} \mathrm{Cl}^{-}\right]$. Chu et al. ${ }^{2}$ noted considerably larger sulfur extraction efficiencies of $40 \%$ for 1-methyl-3-octylimidazolium tetrafluoroborate $\left[(\mathrm{MOIm})^{+}\left(\mathrm{BF}_{4}\right)^{-}\right]$ and 1-octylpyridinium tetrafluoroborate $\left[(\mathrm{OPy})^{+}\left(\mathrm{BF}_{4}\right)^{-}\right]$at an equimass RTIL-to-feed ratio. Additional experimental ${ }^{3-6}$ and theoretical ${ }^{7}$ studies have further documented that the solubilizing properties and absorption capacities of ionic liquids depend on the polarity, shape, and size of the composite cation and anion.

The present study continues our characterization of the solubilizing properties of RTILs. Previously we have reported linear free energy relationship (LFER) correlations for the gasto-RTIL partition coefficients, $K$, for gas and organic vapors dissolved in RTILs ${ }^{8-10}$

$$
\begin{aligned}
\log K=c_{\text {cation }}+c_{\text {anion }}+\left(e_{\text {cation }}+e_{\text {anion }}\right) E+ & \\
\left(s_{\text {cation }}+s_{\text {anion }}\right) S+\left(a_{\text {cation }}+a_{\text {anion }}\right) A+ & \left(b_{\text {cation }}+b_{\text {anion }}\right) B+ \\
& \left(l_{\text {cation }}+l_{\text {anion }}\right) L
\end{aligned}
$$

and for the partitioning of solutes between water and a RTIL, where $P$ is the water-to-RTIL partition coefficient

\footnotetext{
* To whom correspondence should be addressed. E-mail: acree@ unt.edu.

University of North Texas.

*University College London.
}

$$
\begin{aligned}
& \log P=c_{\text {cation }}+c_{\text {anion }}+\left(e_{\text {cation }}+e_{\text {anion }}\right) E+ \\
& \left(s_{\text {cation }}+s_{\text {anion }}\right) S+\left(a_{\text {cation }}+a_{\text {anion }}\right) A+\left(b_{\text {cation }}+b_{\text {anion }}\right) B+ \\
& \quad\left(v_{\text {cation }}+v_{\text {anion }}\right) V
\end{aligned}
$$

both based on the Abraham model. The independent variables in eqs 1 and 2 are solute descriptors as follows: $E$ and $S$ refer to the excess molar refraction in units of $\left(\mathrm{cm}^{3} \mathrm{~mol}^{-1}\right) / 10$ and dipolarity/polarizability descriptors of the solute, respectively, $A$ and $B$ are measures of the solute hydrogen-bond acidity and basicity, $V$ is the McGowan volume in units of $\left(\mathrm{cm}^{3} \mathrm{~mol}^{-1}\right) /$ 100 , and $L$ is the logarithm of the gas-to-hexadecane partition coefficient at $298.15 \mathrm{~K}$. The regression coefficients and constants are determined by regression analyses of the experimental data for the given partition process. To date, we have determined equation coefficients for 12 different cations and for eight different anions using a database that contained more than 1100 experimental $\log K$ and 1100 experimental $\log P$ values derived from solubility and activity coefficient measurements. The derived ion-specific equation coefficients described the observed $\log K$ and $\log P$ data to within a standard deviation of $\mathrm{SD}=$ 0.14 and $\mathrm{SD}=0.15 \log$ units, respectively. ${ }^{8-13}$

The major advantage of splitting the equation coefficients into individual cation-specific and anion-specific contributions is that one can make predictions for more RTILs. Normally one needs partition coefficient data for $40-50$ solutes dissolved in a given RTIL to develop a RTIL-specific Abraham model correlation. By combining all of the experimental data for a RTIL containing, for example, either a 1-methyl-3-octylimidazolium cation, $(\mathrm{MOIm})^{+}$, and trifluoromethane-sulfonate anion, (Trif) $)^{-}$, it may be possible to calculate (MOIm) ${ }^{+}$-specific and (Trif) ${ }^{-}$-specific equation coefficients where there was too few data points for the $(\mathrm{MOIm})^{+}(\text {Trif })^{-}$ionic liquid to develop a meaningful correlation. The computational methodology that we proposed permits us to calculate more ion-specific equation coefficients as more experimental data become available in the future, and the basic computational methodology can be applied to LFERs that employ different kinds/types of solute descriptors.

The Abraham model correlations that we have developed for RTILs pertain to $298.15 \mathrm{~K}$. Manufacturing applications and chemical separation processes are not restricted to $298.15 \mathrm{~K}$. 
In fact the nitrogen removal studies mentioned above were performed at $333 \mathrm{~K}$. There is a growing need to estimate partitioning properties at other temperatures as well. From a thermodynamic standpoint, the gas-to-condensed-phase partition coefficient, $K$, and water-to-organic solvent partition coefficient, $P$, can be estimated

$\log K($ at $T)-\log K($ at $298.15 \mathrm{~K})=\frac{-\Delta H_{\text {solv }}}{2.303 R}(1 / T-1 / 298.15)$

$\log P(\operatorname{at} T)-\log P($ at $298.15 \mathrm{~K})=\frac{-\Delta H_{\text {trans }}}{2.303 R}(1 / T-1 / 298.15)$

at other temperatures from the universal gas constant $(R)$, measured partition coefficient data at $298.15 \mathrm{~K}$ and the solute's enthalpy of solvation, $\Delta H_{\text {solv }}$, or enthalpy of transfer, $\Delta H_{\text {trans }}$, between the two condensed phases. The enthalpy of transfer needed in eq 4 is defined as

$$
\Delta H_{\text {trans }}=\Delta H_{\text {solv,org }}-\Delta H_{\text {solv, }, \mathrm{W}}
$$

the difference in the enthalpy of solvation of the solute in the specified organic solvent minus its enthalpy of solvation in water. The above equations assume zero heat capacity changes.

Here and elsewhere, $N$ corresponds to the number of solutes, $R$ denotes the correlation coefficient, $\mathrm{SD}$ is the standard deviation, and $F$ corresponds to the Fisher $F$-statistic.

In the present study we examine the applicability of the Abraham solvation parameter model as a mathematical correlation for describing the enthalpy of solvation data of organic solutes and ionic gases in room-temperature ionic liquids. Both the RTIL-specific and ion-specific equation coefficient forms of the Abraham model are considered. Equation coefficients are reported for nine cations and eight anions. The calculated coefficients can be combined to give mathematical expressions capable of predicting $\Delta H_{\text {solv }}$ in 72 different RTILs.

\section{Data Set and Computation Methodology}

Our search of the published chemical and engineering literature found several papers ${ }^{22-53}$ that reported experimental infinite dilution activity coefficient data, $\gamma_{\text {solute }}{ }^{\infty}$, for solutes dissolved in 1-methyl-3-ethylimidazolium bis(trifluoromethylsulfonyl)imide $\left[(\mathrm{MEIm})^{+}\left[(\mathrm{Tf})_{2} \mathrm{~N}\right]^{-}\right]$, 1-methyl-3-butylimidazolium bis(trifluoromethylsulfonyl)imide $\left[(\mathrm{MBIm})^{+}\left[(\mathrm{Tf})_{2} \mathrm{~N}\right]^{-}\right]$, 1-methyl-3-hexylimidazolium bis(trifluoromethylsulfonyl)imide $\left[(\mathrm{MHIm})^{+}\left[(\mathrm{Tf})_{2} \mathrm{~N}\right]^{-}\right]$, 1-methyl-3-butylimidazolium hexafluorophosphate $\left[(\mathrm{MBim})^{+}\left(\mathrm{PF}_{6}\right)^{-}\right], 4$-methyl- $N$-butylpyridinium tetrafluoroborate $\left[(\mathrm{BMPy})^{+}\left(\mathrm{BF}_{4}\right)^{-}\right]$, 1,2-dimethyl-3-ethylimidazolium bis(triflluoromethylsulfonyl)imide $\left[\left(\mathrm{M}_{2} \mathrm{EIm}\right)^{+}\left[(\mathrm{Tf})_{2} \mathrm{~N}\right]^{-}\right]$, 1-methyl-3-ethylimidazolium ethylsulfate $\left[(\mathrm{MEIm})^{+}\left[\mathrm{EtSO}_{4}\right]^{-}\right]$, trimethylbutylammonium bis(trifluoromethylsulfonyl)imide $\left[\left(\mathrm{M}_{3} \mathrm{BAm}\right)^{+}\left[(\mathrm{Tf})_{2} \mathrm{~N}\right]^{-}\right]$, 1-methyl-3-ethylimidazolium thiocyanate $\left[(\mathrm{MEIm})^{+}(\mathrm{SCN})^{-}\right], 1$-methyl-3-ethylimidazoium tetrafluoroborate $\left[(\mathrm{MEIm})^{+}\left(\mathrm{BF}_{4}\right)^{-}\right]$, 1-methyl-3-butylimidazoium tetrafluoroborate $\left[(\mathrm{MBIm})^{+}\left(\mathrm{BF}_{4}\right)^{-}\right], 1$-methyl-3-butylimidazolium thiocyanate $\left[(\mathrm{MBIm})^{+}(\mathrm{SCN})^{-}\right]$, 1-methyl-3-ethylimidazoium trifluoroacetate $\left[(\mathrm{MEIm})^{+}\left(\mathrm{F}_{3} \mathrm{Ac}\right)^{-}\right]$, triethylsulfonium bis(trifluoromethylsulfonyl)imide $\left[\left(\mathrm{Et}_{3} \mathrm{~S}\right)^{+}\left[(\mathrm{Tf})_{2} \mathrm{~N}\right]^{-}\right]$, 1-methyl-3-octylimidazolium bis(trifluoromethylsulfonyl)imide $\left[(\mathrm{MOIm})^{+}-\right.$ $\left.\left[(\mathrm{Tf})_{2} \mathrm{~N}\right]^{-}\right]$, 1-butyl-1-methylpyrrolidinium trifluoromethylsulfonate $\left[(\mathrm{BMPyr})^{+}[\mathrm{Trif}]^{-}\right], 1$-methyl-3-hexylimidazoium trifluoromethylsulfonate $\left[(\mathrm{MHIm})^{+}\left(\right.\right.$Trif $\left.^{-}\right]$, 1-methyl-3-hexylimidazoium tetrafluoroborate $\left[(\mathrm{MHIm})^{+}\left(\mathrm{BF}_{4}\right)^{-}\right], 1$-methyl-3-octylimidazolium tetrafluoroborate $\left[(\mathrm{MOIm})^{+}\left(\mathrm{BF}_{4}\right)^{-}\right]$, and 1-methyl-3-ethylimidazoium nitrate $\left[(\mathrm{MEIm})^{+}\left(\mathrm{NO}_{3}\right)^{-}\right]$. The experimental $\gamma_{\text {solute }}{ }^{\infty}$ values were obtained through gas chromatographic retention time measurements on RTIL stationary-phase solvents. As part of the chromatographic study the authors measured the retention times at several temperatures and calculated the solute's molar enthalpy of solution in the RTIL from the variation of $\gamma_{\text {solute }}{ }^{\infty}$ with temperature; i.e., $\Delta H^{\text {ex, } \infty}=R \partial \ln \gamma_{\text {solute }} / \partial(1 / T)$. Enthalpies of solution determined in this fashion assume that $\Delta H^{\mathrm{ex}, \infty}$ is independent of temperature over the range of the experimental measurements. Most of the experimental $\gamma_{\text {solute }}{ }^{\infty}$ measurements were performed over a $30 \mathrm{~K}$ temperature range, and we have taken the calculated $\Delta H^{\mathrm{ex}, \infty}$ values to be at the median temperature of the respective $\gamma_{\text {solute }}{ }^{\infty}$ measurements. For the majority of measurements the median temperature corresponded to $323 \pm 5 \mathrm{~K}$.

The published $\Delta H^{\text {ex, } \infty}$ values were converted to gas-to-RTIL enthalpies of transfer by

$$
\Delta H_{\mathrm{solv}}=\Delta H^{\mathrm{ex}, \infty}-\Delta H_{\mathrm{vap}, 323 \mathrm{~K}}
$$

subtracting the solute's enthalpy of vaporization $\Delta H_{\mathrm{vap}, 323 \mathrm{~K}} \cdot{ }^{14}$ The organic solutes were liquids at $323 \mathrm{~K}$. Enthalpies of vaporization used in this conversion were based on the published $\Delta H_{\text {vap }, 323 \mathrm{~K}}$ data from the compilation by Chickos and Acree, ${ }^{14}$ and were converted to a common temperature of $323 \mathrm{~K}$ using the method recommended by the authors. The correction of $\Delta H_{\text {vap }}$ from 298 to $323 \mathrm{~K}$ amounted to less than $-2.5 \mathrm{~kJ} / \mathrm{mol}$ for the solutes considered here, which is believed to be less than the experimental uncertainty in the $\Delta H^{\mathrm{ex}, \infty}$ data.

In total, experimental $\Delta H^{\mathrm{ex}, \infty}$ values were found for 675 solute-RTIL pairs. The experimental $\Delta H^{\mathrm{ex}, \infty}$ values were converted to enthalpies of solvation through eq 10. For convenience, we have compiled in Table S1 (Supporting Information) the entire database of $\Delta H_{\text {solv }}$ values, along with the solute descriptors of all of the compounds considered in the present study. The solute descriptors are of experimental origin and came from our solute descriptor database, which now contains values for more than 4000 different organic and organometallic compounds.

A few additional comments concerning the computational methodology that we will employ in this study. As noted previously, the cation-specific and anion-specific coefficients in eqs 1 and 2 are paired. Each cation-specific coefficient goes together with its anion-specific counterpart to make up a summed value that the five solute descriptors are multiplied by. If one were to perform a regression analysis on eqs 1 and 2, the statistical software would generate numerical equation coefficients based on some reference point. The reference point would likely depend on the particular database used and the software's built-in convergence routine. Calculation of additional ion values at some later time would be difficult as there is no guarantee that the next regression analyses would find the same reference point. In accordance with the computational methodology that we recommended in our earlier papers, ${ }^{8-10}$ we have set the anion-specific equation coefficients of $\left[(\mathrm{Tf})_{2} \mathrm{~N}\right]^{-}$equal to zero. In many respects our fixed reference point is analogous to how the chemical potentials of the individual ions are determined. By convention the chemical potential of the hydrogen ion is defined to be zero, and the values of all other 
Table 1. Abraham Model Equation Coefficients for the Enthalpies of Solvation of Solutes in $(\mathrm{MBIm})^{+}\left[(\mathrm{Tf})_{2} \mathrm{~N}\right]^{-},(\mathrm{MHIm})^{+}\left[(\mathrm{Tf})_{2} \mathrm{~N}\right]^{-}$, and $\left.\left(\mathbf{M}_{3} \mathbf{B A m}\right)^{+}\left[(\mathbf{T f})_{2} \mathbf{N}\right]^{-}\right)$

\begin{tabular}{|c|c|c|c|c|c|c|c|c|c|c|c|}
\hline ionic liquid solvent & $c$ & $e$ & $s$ & $a$ & $b$ & $v$ & $l$ & $N$ & SD & $R^{2}$ & $F$ \\
\hline \multirow[t]{2}{*}{$(\mathrm{MBIm})^{+}\left[(\mathrm{Tf})_{2} \mathrm{~N}\right]^{-}$} & $\begin{array}{c}-5.612 \\
(0.857)\end{array}$ & $\begin{array}{c}2.364 \\
(1.686)\end{array}$ & $\begin{array}{c}-8.393 \\
(2.269)\end{array}$ & $\begin{array}{r}-20.478 \\
(2.613)\end{array}$ & $\begin{array}{r}-11.002 \\
(2.837)\end{array}$ & & $\begin{array}{r}-7.381 \\
(0.209)\end{array}$ & 53 & 1.49 & 0.968 & 287.8 \\
\hline & $\begin{array}{c}0.249 \\
(1.148)\end{array}$ & $\begin{array}{c}-8.159 \\
(1.868)\end{array}$ & $\begin{array}{r}-11.491 \\
(2.604)\end{array}$ & $\begin{array}{r}-20.296 \\
(2.296)\end{array}$ & $\begin{array}{r}-13.875 \\
(3.125)\end{array}$ & $\begin{array}{r}-26.299 \\
(0.851)\end{array}$ & & 53 & 1.70 & 0.959 & 220.9 \\
\hline \multirow[t]{2}{*}{$(\mathrm{MHIm})^{+}\left[(\mathrm{Tf})_{2} \mathrm{~N}\right]^{-}$} & $\begin{array}{c}-6.226 \\
(0.704)\end{array}$ & $\begin{array}{c}0.583 \\
(1.565)\end{array}$ & $\begin{array}{c}-6.814 \\
(1.918)\end{array}$ & $\begin{array}{r}-18.335 \\
(2.350)\end{array}$ & $\begin{array}{r}-10.722 \\
(2.292)\end{array}$ & & $\begin{array}{c}-7.628 \\
(0.183)\end{array}$ & 55 & 1.38 & 0.977 & 422.8 \\
\hline & $\begin{array}{c}-0.015 \\
(0.980)\end{array}$ & $\begin{array}{r}-12.093 \\
(1.762)\end{array}$ & $\begin{array}{r}-7.367 \\
(2.244)\end{array}$ & $\begin{array}{r}-15.789 \\
(2.715)\end{array}$ & $\begin{array}{r}-15.536 \\
(2.645)\end{array}$ & $\begin{array}{r}-27.377 \\
(0.770)\end{array}$ & & 55 & 1.61 & 0.969 & 308.0 \\
\hline$\left(\mathrm{M}_{3} \mathrm{BAm}\right)^{+}\left[(\mathrm{Tf})_{2} \mathrm{~N}\right]^{-}$ & $\begin{array}{c}-1.158 \\
(1.000)\end{array}$ & $\begin{array}{c}-7.091 \\
(1.720)\end{array}$ & $\begin{array}{r}-15.020 \\
(2.325)\end{array}$ & $\begin{array}{r}-25.483 \\
(2.675)\end{array}$ & $\begin{array}{c}-6.221 \\
(2.722)\end{array}$ & $\begin{array}{r}-24.671 \\
(0.745)\end{array}$ & & 51 & 1.41 & 0.966 & 253.2 \\
\hline
\end{tabular}

ions are computed relative to this defined thermodynamic reference state.

\section{Results and Discussion}

There is sufficient experimental $\Delta H_{\text {solv }}$ data for 1-methyl-3butylimidazolium bis(trifluoromethylsulfonyl)imide (53 values), 1-methyl-3-hexylimidazolium bis(trifluoromethylsulfonyl)imide (55 values), and trimethylbutylammonium bis(trifluoromethylsulfonyl)imide (51 values) to develop RTIL-specific Abraham model correlations. These RTIL-specific correlations provide a benchmark to use in assessing how much predictive accuracy is lost whenever the equation coefficients are split into separate cation-specific and anion-specific contributions. The $\Delta H_{\text {solv }}$ values in Table S1 for these three RTILs were analyzed according to the Abraham model with the dependent variable being $\Delta H_{\text {solv }}$. The equation coefficients for the three RTILs are given in Table 1, along with the corresponding statistical information, where $N$ corresponds to the number of solutes, $R^{2}$ denotes the squared correlation coefficient, SD is the standard deviation, and $F$ corresponds to the Fisher $F$-statistic. The standard errors in the calculated coefficients are given in parentheses below the respective equation coefficient. Regression analyses were performed using SPSS statistical software.

Examination of the statistical information reveals that all six equations are statistically very good given the number of compounds present in the database and the chemical diversity of the different organic solutes studied. Standard deviations were in the range of $1.40-1.70 \mathrm{~kJ} / \mathrm{mol}$ for the three data sets that span ranges of $\Delta H_{\text {solv }}$ of about $40 \mathrm{~kJ} / \mathrm{mol}$. For two of the three RTILs the correlations that included the $L$-descriptor were slightly better than their $V$-descriptor counterpart. From a thermodynamic point-of-view eq 1 is the enthalpic temperature derivative of the Abraham model's gas-to-RTIL transfer equation. The correlations that contain the $V$-descriptor might be more useful in some predictive applications in instances where the $L$-descriptor is not known. Equation 2 correlations use the McGowan volume, $V$-descriptor, which is easily calculable from the individual atomic sizes and numbers of bonds in the molecule. ${ }^{15}$ See Figure 1 for a presented plot of calculated values of $\Delta H_{\text {solv }}$ based on eq 1 (equation coefficients in Table 1) against the observed values for $(\mathrm{MBIm})^{+}\left[(\mathrm{Tf})_{2} \mathrm{~N}\right]^{-}$.

The six RTIL-specific correlations derived above provide a benchmark to use in assessing how much predictive accuracy is likely lost whenever the equation coefficients are separated into individual cation-specific and anion-specific contributions as will now be done. The 675 experimental $\Delta H_{\text {solv }}$ values in Table S1 were analyzed collectively by regression analysis in accordance to eqs 1 and 2 of the Abraham model (with the dependent variable being $\Delta H_{\text {solv }}$ ). The calculated cation-specific and anion-specific equation coefficients for eqs 1 and 2 are listed in Tables 2 and 3, respectively. The statistical information for the respective correlations is as follows: $N=675, \mathrm{SD}=1.629$, $R^{2}=0.998, R_{\text {adj }}^{2}=0.998$, and $F=2860$ for eq 1 and $N=$ $675, \mathrm{SD}=1.726, R^{2}=0.998, R_{\text {adj }}^{2}=0.997$, and $F=2546$ for eq 2. Equations 1 and 2 describe the experimental enthalpies of solvation of the organic solutes in RTILs to within standard deviations of 1.63 and $1.73 \mathrm{~kJ} / \mathrm{mol}$, which are comparable to the standard deviations noted for the six benchmark RTILspecific correlations given in Table 1 . The ion-specific equation coefficients for $(\mathrm{MBIm})^{+},(\mathrm{MHIm})^{+},\left(\mathrm{M}_{3} \mathrm{BAm}\right)^{+}$, and $\left[(\mathrm{Tf})_{2} \mathrm{~N}\right]^{-}$, when substituted into eq 1 , back-calculated the observed $\Delta H_{\text {solv }}$ values in $(\mathrm{MBIm})^{+}\left[(\mathrm{Tf})_{2} \mathrm{~N}\right]^{-},(\mathrm{MHIm})^{+}\left[(\mathrm{Tf})_{2} \mathrm{~N}\right]^{-}$, and $\left(\mathrm{M}_{3} \mathrm{BAm}\right)^{+}$$\left[(\mathrm{Tf})_{2} \mathrm{~N}\right]^{-}$to within standard deviations of $1.61,1.43$, and 1.50 $\mathrm{kJ} / \mathrm{mol}$. There is little (if any) loss in predictive ability from our use of cation-specific and anion-specific equation coefficients. (See Figures 2 and 3 for a graphical plot of the experimental $\Delta H_{\text {solv }}$ data versus calculated values based on eqs 1 and 2.) For information purposes, an uncertainty/error of \pm 2 $\mathrm{kJ} / \mathrm{mol}$ in the enthalpy of solvation results in an error of slightly less than $0.04 \log$ units in extrapolating a $\log K$ value measured at $323.15-338.15 \mathrm{~K}$. This level of error will be sufficient for most practical chemical and engineering applications.

Standard errors in the coefficients are given in parentheses next to the respective values in Tables 2 and 3. For the most part, the larger standard errors were noted in the equation coefficients for those ions for which experimental data were limited. The number of data points for the individual ions ranged from a minimum of $27 \Delta H_{\text {solv }}$ values for $\left(\mathrm{F}_{3} \mathrm{Ac}\right)^{-}$anion to more than $175 \Delta H_{\text {solv }}$ values for both $(\mathrm{BMIm})^{+}$and $(\mathrm{MEIm})^{+}$cations

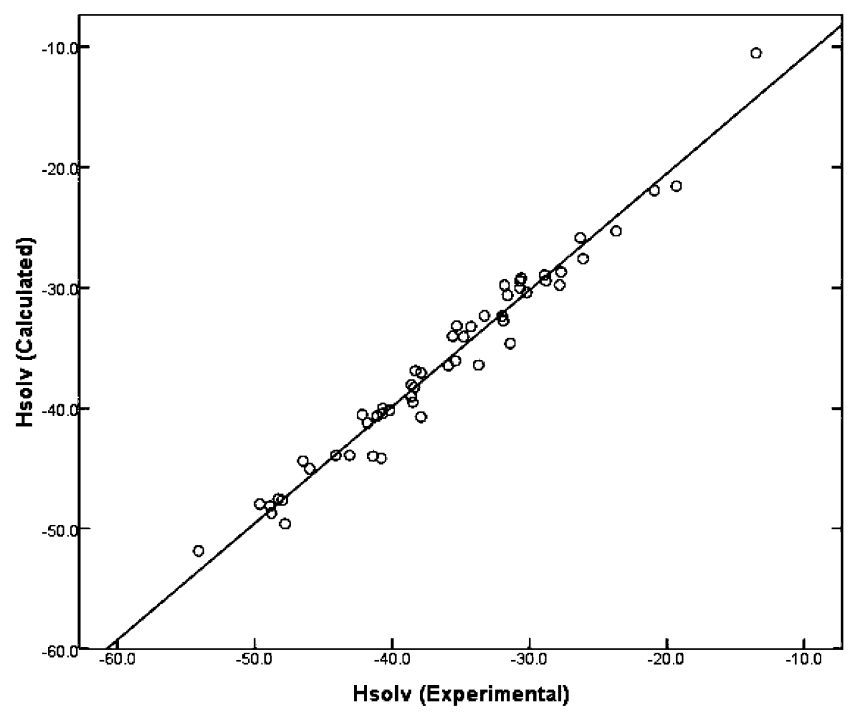

Figure 1. Plot of the calculated values of $\Delta H_{\text {solv }}$ for $(\mathrm{MBIm})^{+}\left[(\mathrm{Tf})_{2} \mathrm{~N}\right]^{-}$ based on eq 1 (coefficients in Table 1) against the experimental values. 
Ind. Eng. Chem. Res., Vol. 48, No. 18, $2009 \mathbf{8 7 0 7}$

Table 2. Cation-Specific and Anion-Specific Equation Coefficients for the Abraham Model Enthalpy of Solvation Correlation (Equation 1)

\begin{tabular}{|c|c|c|c|c|c|c|}
\hline ion & $c_{\text {ion }}$ & $e_{\text {ion }}$ & $s_{\text {ion }}$ & $a_{\text {ion }}$ & $b_{\text {ion }}$ & $l_{\text {ion }}$ \\
\hline \multicolumn{7}{|c|}{ Cations $^{a}$} \\
\hline$(\operatorname{MEIm})^{+}(N=190)^{b}$ & $-6.560(0.913)$ & $1.164(1.790)$ & $-11.642(1.970)$ & $-22.158(2.388)$ & $-8.575(1.822)$ & $-6.961(0.280)$ \\
\hline$(\mathrm{BMIm})^{+}(N=177)$ & $-5.658(0.774)$ & $0.151(1.605)$ & $-9.518(2.252)$ & $-21.814(2.566)$ & $-9.211(2.810)$ & $-7.326(0.203)$ \\
\hline$(\mathrm{MHIm})^{+}(N=66)$ & $-5.128(0.794)$ & $1.207(1.818)$ & $-8.438(2.283)$ & $-19.755(2.761)$ & $-10.290(2.759)$ & $-7.773(0.215)$ \\
\hline$(\mathrm{MOIm})^{+}(N=62)$ & $-9.153(1.190)$ & $-3.884(2.682)$ & $0.686(3.209)$ & $-19.885(3.065)$ & $-9.464(2.990)$ & $-7.058(0.361)$ \\
\hline$\left(\mathrm{M}_{3} \mathrm{BAm}\right)^{+}(N=51)$ & $-7.255(0.989)$ & $1.352(2.083)$ & $-9.405(2.780)$ & $-22.715(3.130)$ & $-7.191(3.215)$ & $-6.761(0.242)$ \\
\hline$\left(\mathrm{M}_{2} \mathrm{EIm}\right)^{+}(N=37)$ & $-0.592(1.602)$ & $4.122(2.140)$ & $-15.849(2.267)$ & $-23.339(2.683)$ & $-7.193(2.056)$ & $-8.667(0.451)$ \\
\hline$(\mathrm{BMPy})^{+}(N=34)$ & $-2.659(1.881)$ & $2.998(3.147)$ & $-13.307(3.696)$ & $-26.094(4.211)$ & $-8.295(3.715)$ & $-8.493(0.543)$ \\
\hline$\left(\mathrm{E}_{3} \mathrm{~S}\right)^{+}(N=28)$ & $-2.913(1.676)$ & $15.064(4.695)$ & $-32.880(7.580)$ & $-15.755(11.197)$ & $-5.551(12.782)$ & $-7.845(0.505)$ \\
\hline$[\mathrm{BMPyr}]^{+}(N=30)$ & $-4.416(1.996)$ & $14.569(4.730)$ & $-28.215(5.991)$ & $-16.388(5.123)$ & $-1.897(5.123)$ & -7.907 (0.619) \\
\hline \multicolumn{7}{|c|}{ Anions $^{c}$} \\
\hline$\left[(\mathrm{Tf})_{2} \mathrm{~N}\right]^{-}(N=319)$ & 0.000 & 0.000 & 0.000 & 0.000 & 0.000 & 0.000 \\
\hline$\left(\mathrm{BF}_{4}\right)^{-}(N=134)$ & $-0.766(0.911)$ & $-1.013(2.245)$ & $-1.501(2.740)$ & $1.388(2.970)$ & $2.334(2.749)$ & $0.545(0.283)$ \\
\hline$\left[\mathrm{PF}_{6}\right]^{-}(N=29)$ & $-7.339(0.997)$ & $5.475(3.331)$ & $-18.938(4.113)$ & $16.492(4.128)$ & $13.139(4.312)$ & $1.399(0.338)$ \\
\hline$\left(\mathrm{EtSO}_{4}\right)^{-}(N=41)$ & $-2.219(1.880)$ & $0.310(2.831)$ & $2.864(3.209)$ & $-15.422(3.948)$ & $2.182(3.469)$ & $0.866(0.444)$ \\
\hline$(\text { Trif })^{-}(N=45)$ & $0.787(1.604)$ & $-1.849(2.644)$ & $-1.982(3.226)$ & $-19.333(3.692)$ & $4.845(3.615)$ & $0.019(0.479)$ \\
\hline$\left(\mathrm{F}_{3} \mathrm{Ac}\right)^{-}(N=27)$ & $6.034(1.922)$ & $11.778(5.030)$ & $-9.665(7.850)$ & $-10.631(11.457)$ & $-15.298(12.918)$ & $-1.954(0.584)$ \\
\hline$\left[\mathrm{NO}_{3}\right]^{-}(N=28)$ & $-3.039(3.340)$ & $3.250(3.121)$ & $-3.831(3.153)$ & $-12.638(4.717)$ & $6.588(2.951)$ & $0.329(0.997)$ \\
\hline$(\mathrm{SCN})^{-}(N=52)$ & $8.841(1.431)$ & $18.965(3.554)$ & $-30.165(4.771)$ & $-22.794(4.222)$ & $13.264(4.431)$ & $-2.301(0.416)$ \\
\hline
\end{tabular}

${ }^{a}$ Cation abbreviations: (BMPy) $)^{+}$is 4-methyl- $N$-butylpyridinium cation; (MEIm) ${ }^{+}$is 1-methyl-3-ethylimidazolium cation; $\left(\mathrm{M}_{2} \mathrm{EIm}^{+}\right.$is 1,2-dimethyl-3-ethylimidazolium cation; $(\mathrm{MBIm})^{+}$is 1-methyl-3-butylimidazolium cation; $(\mathrm{MHIm})^{+}$is 1-methyl-3-hexylimidazolium cation; $\left(\mathrm{M}_{3} \mathrm{BAm}^{+}\right.$ is trimethylbutylammonium cation; $(\mathrm{MOIm})^{+}$is 1-methyl-3-octylimidazolium cation; $(\mathrm{BMPyr})^{+}$is 1-butyl-1-methylpyrrolidinium cation; and $\left(\mathrm{E}_{3} \mathrm{~S}\right)^{+}$is triethylsulphonium cation. ${ }^{b}$ Number of experimental data points associated with the specified ion. ${ }^{c}$ Anion abbreviations: $\left[(\mathrm{Tf})_{2} \mathrm{~N}\right]^{-}$is bis(trifluoromethylsulfonyl)imide anion; $\left(\mathrm{BF}_{4}\right)^{-}$is tetrafluoroborate anion; $\left(\mathrm{PF}_{6}\right)^{-}$is hexafluorophosphate anion; $\left(\mathrm{NO}_{3}\right)^{-}$is nitrate anion; $(\mathrm{Trif})^{-}$is the trifluoromethanesulfonate anion; $\left(\mathrm{F}_{3} \mathrm{Ac}\right)^{-}$is the trifluoroacetate anion; $\left(\mathrm{EtSO}_{4}\right)^{-}$is ethylsulfate anion; and $(\mathrm{SCN})^{-}$is thiocyanate anion.

Table 3. Cation-Specific and Anion-Specific Equation Coefficients for the Abraham Model Enthalpy of Solvation Correlation (Equation 2)

\begin{tabular}{|c|c|c|c|c|c|c|}
\hline $\operatorname{ion}^{a}$ & $c_{\text {ion }}$ & $e_{\text {ion }}$ & $s_{\text {ion }}$ & $a_{\text {ion }}$ & $b_{\text {ion }}$ & $v_{\text {ion }}$ \\
\hline$(\operatorname{MEIm})^{+}(N=190)^{b}$ & $-1.749(1.177)$ & $-8.977(1.720)$ & $-14.808(2.128)$ & $-25.587(2.592)$ & $-7.751(1.939)$ & $-24.138(1.056)$ \\
\hline$(\mathrm{MHIm})^{+}(N=66)$ & $0.648(1.006)$ & $-12.176(1.866)$ & $-8.272(2.423)$ & $-16.770(2.896)$ & $-15.303(2.893)$ & $-27.552(0.819)$ \\
\hline$(\mathrm{MOIm})^{+}(N=62)$ & $-5.403(1.519)$ & $-15.361(2.767)$ & $-1.760(3.441)$ & $-20.081(3.282)$ & $-9.205(3.169)$ & $-23.446(1.353)$ \\
\hline$\left(\mathrm{M}_{3} \mathrm{BAm}\right)^{+}(N=51)$ & $-1.158(1.253)$ & $-7.091(2.155)$ & $-15.020(3.002)$ & $-25.483(3.352)$ & $-6.221(3.412)$ & $-24.671(0.933)$ \\
\hline$\left(\mathrm{M}_{3} \mathrm{EIm}\right)^{+}(N=37)$ & $4.006(1.969)$ & $-5.855(2.055)$ & $-21.604(2.579)$ & $-28.854(2.962)$ & $-3.145(2.198)$ & $-29.304(1.650)$ \\
\hline$(\mathrm{BMPyr})^{+}(N=30)$ & $4.658(2.547)$ & $-5.022(4.569)$ & $-20.768(6.257)$ & $-19.252(5.444)$ & $-10.633(5.380)$ & $-30.547(2.303)$ \\
\hline \multicolumn{7}{|c|}{ Anions } \\
\hline$\left[(\mathrm{Tf})_{2} \mathrm{~N}\right]^{-}(N=319)$ & 0.000 & 0.000 & 0.000 & 0.000 & 0.000 & 0.000 \\
\hline$\left(\mathrm{BF}_{4}\right)^{-}(N=134)$ & $1.068(1.208)$ & $2.548(2.279)$ & $-5.407(2.967)$ & $-0.955(3.199)$ & $4.255(2.924)$ & $-0.117(1.100)$ \\
\hline$\left(\mathrm{PF}_{6}\right)^{-}(N=29)$ & $-4.824(1.335)$ & $11.775(3.453)$ & $-26.835(4.399)$ & $10.191(4.426)$ & $20.125(4.592)$ & $1.930(1.412)$ \\
\hline$\left(\mathrm{EtSO}_{4}\right)^{-}(N=41)$ & $-1.366(2.388)$ & $5.735(2.868)$ & $-1.987(3.584)$ & $-16.610(4.332)$ & $4.745(3.684)$ & $1.837(1.715)$ \\
\hline
\end{tabular}

${ }^{a}$ Cation and anion abbreviations are given in footnote a to Table 2. ${ }^{b}$ Number of experimental data points associated with the specified ion.

and the $\left[(\mathrm{Tf})_{2} \mathrm{~N}\right]^{-}$anion. Solutes were typically a few inert gases and diatomic gas molecules, linear (up to dodecane) and cyclic alkanes, alkenes, alkynes, alkylbenzenes, linear and branched alcohols, linear and cyclic monoethers (plus 1,4-dioxane), chlorinated methanes and a few of the smaller aldehydes, ketones, and alkyl esters. The solute descriptor space defined by these compounds would be $E=0.000$ to $E=0.850 ; S=$ 0.000 to $S=0.900 ; A=0.000$ to $A=0.430 ; B=0.000$ to $B$ $=0.650 ; V=0.109$ to $V=1.800$; and $L=-1.200$ to $L=$ 5.700. There were very few solutes having large solute descriptor values, and the lack of highly acidic and basic compounds in the database contributed in part to the large observed standard errors. Large standard errors were similarly noted in the ion-specific equation coefficients for our initial $\log K$ and $\log P$ Abraham model correlations. The standard errors did decrease in magnitude when additional $\log K$ and $\log P$ values were added to the database. We expect the same to happen with the $\Delta H_{\text {solv }}$ correlations. Despite these short- comings we believe that the experimental $\Delta H_{\text {solv }}$ database was sufficient to demonstrate the applicability of the proposed method of correlating enthalpies of solvation with the cationspecific and anion-specific equation coefficient form of the basic Abraham model. We expect the derived correlations to provide reasonable estimates of the enthalpies of solvation for additional solutes dissolved in RTILs containing the nine cations and eight anions considered here, provided that solute's descriptors are within the predictive area of chemical space covered by eqs 1 and 2 .

During the course of our regression analyses, we discovered that the published experimental $\Delta H_{\text {solv }}$ data for 1-propyl-2,3dimethylimidazolium tetrafluoroborate ${ }^{16,17}\left[\left(\mathrm{PM}_{2} \mathrm{Im}\right)^{+}\left(\mathrm{BF}_{4}\right)^{-}\right]$ could not be correlated using the ion-specific form of the Abraham model. The 34 experimental $\Delta H_{\text {solv }}$ data points in Table S4 (Supporting Information) were analyzed in terms of the basic model to give 


$$
\begin{gathered}
\Delta H_{\text {solv }}(\mathrm{kJ} / \mathrm{mol})=-1.188(5.912)-1.103(7.858) E- \\
33.961(9.246) S-43.349(10.667) A-6.092(9.531) B- \\
2.080(1.730) L
\end{gathered}
$$

(with $N=34, \quad \mathrm{SD}=5.433, \quad R^{2}=0.831$,

$$
\left.R_{\text {adj }}^{2}=0.801, \quad F=27.51\right)
$$

$\Delta H_{\text {solv }}(\mathrm{kJ} / \mathrm{mol})=-1.506(6.924)-3.934(7.179) E-$

$$
\begin{array}{r}
33.988(9.877) S-42.211(10.747) A-6.629(9.590) B- \\
5.736(5.968) V
\end{array}
$$

(with $N=34, \quad \mathrm{SD}=5.48, \quad R^{2}=0.828$,

$$
\left.R_{\text {adj }}^{2}=0.797, \quad F=26.92\right)
$$

The derived correlations had much larger standard deviations $(\mathrm{SD}=5.43 \mathrm{~kJ} / \mathrm{mol}$ and $\mathrm{SD}=5.48 \mathrm{~kJ} / \mathrm{mol})$ and much lower $R^{2}$ values $\left(R^{2}=0.831\right.$ and $\left.R^{2}=0.828\right)$ than were noted for $(\mathrm{MBIm})^{+}\left[(\mathrm{Tf})_{2} \mathrm{~N}\right]^{-},(\mathrm{MHIm})^{+}\left[(\mathrm{Tf})_{2} \mathrm{~N}\right]^{-}$, and $\left(\mathrm{M}_{3} \mathrm{BAm}\right)^{+}\left[(\mathrm{Tf})_{2} \mathrm{~N}\right]^{-}$. See Figures 4 and 5 for a graphical comparison of the experimental $\Delta H_{\text {solv }}$ data versus calculated values based on eqs 7 and 8. In both graphs several of the experimental data points

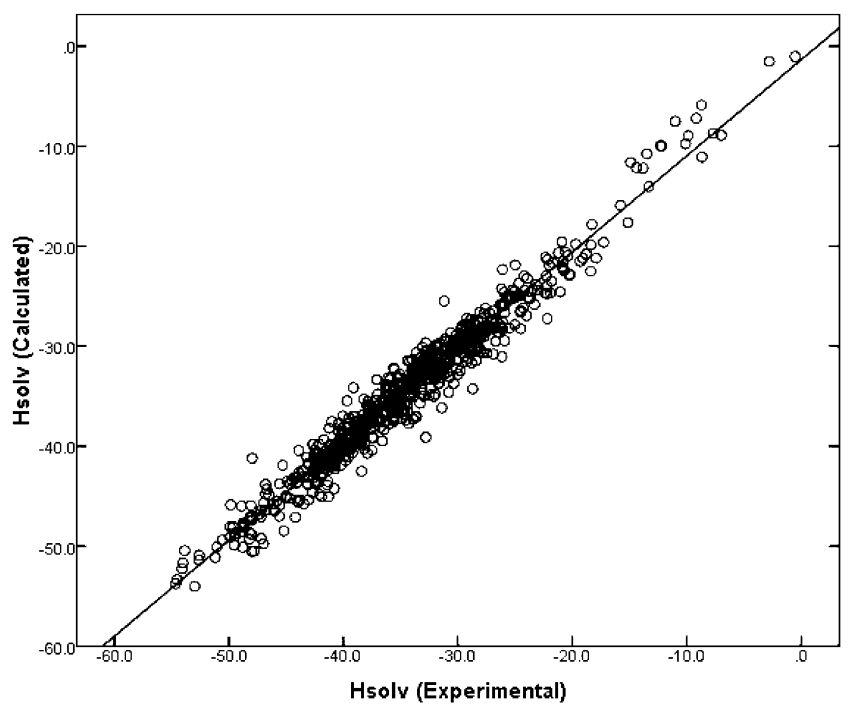

Figure 2. Comparison of experimental $\Delta H_{\text {solv }}$ data to calculated values based on eq 1.



Figure 3. Comparison of experimental $\Delta H_{\text {solv }}$ data to calculated values based on eq 2.



Figure 4. Comparison of experimental $\Delta H_{\text {solv }}$ data for $\left(\mathrm{PM}_{2} \mathrm{Im}\right)^{+}\left(\mathrm{BF}_{4}\right)^{-}$to calculated values based on eq 7 .

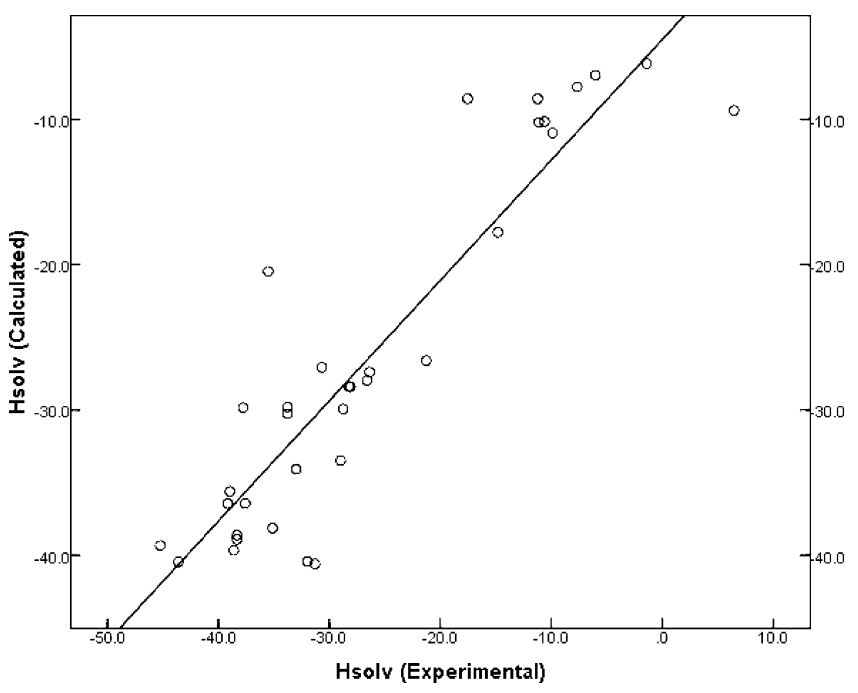

Figure 5. Comparison of experimental $\Delta H_{\text {solv }}$ data for $\left(\mathrm{PM}_{2} \mathrm{Im}\right)^{+}\left(\mathrm{BF}_{4}\right)^{-}$to calculated values based on eq 8 .

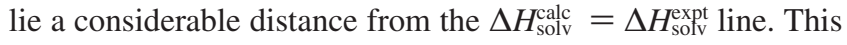
is noticeable from the predictive ability noted for the benchmark correlations derived for $(\mathrm{MBIm})^{+}\left[(\mathrm{Tf})_{2} \mathrm{~N}\right]^{-},(\mathrm{MHIm})^{+}\left[(\mathrm{Tf})_{2} \mathrm{~N}\right]^{-}$, and $\left(\mathrm{M}_{3} \mathrm{BAm}\right)^{+}\left[(\mathrm{Tf})_{2} \mathrm{~N}\right]^{-}$. We suspect that the reason for the poor mathematical correlations relates to the quality of the experimental data. The Abraham model did provide very good mathematical descriptions of the $\Delta H_{\text {solv }}$ data for all other RTILs except for $\left(\mathrm{PM}_{2} \mathrm{Im}\right)^{+}\left(\mathrm{BF}_{4}\right)^{-}$.

To assess the predictive capability of eqs 1 and 2, we divided the 675 data points into a training set and a test set by selecting every other data point in the complete database. The selection ensured that each ion was equally represented in both the training and test sets. The selected data points became the training set, and the compounds that were left served as the test set. Analysis of the 338 experimental data points in the training set gave the cation-specific and anionspecific equation coefficients listed in Tables $2 \mathrm{~S}$ and $3 \mathrm{~S}$ (Supporting Information), with $\mathrm{SD}=1.45$ and $\mathrm{SD}=1.60$ $\mathrm{kJ} / \mathrm{mol}, R^{2}=0.999$ and $R^{2}=0.998$, and $F=2920$ and $F=$ 1266 for eqs 1 and 2, respectively. The training set equation coefficients were then used to predict $\Delta H_{\text {solv }}$ values for the remaining 337 compounds in the test set. For the predicted 
and experimental values we find $\mathrm{SD}=2.02 \mathrm{~kJ} / \mathrm{mol}$, average absolute error $(\mathrm{AAE})=1.47 \mathrm{~kJ} / \mathrm{mol}$, and average error $(\mathrm{AE})$ $=0.075 \mathrm{~kJ} / \mathrm{mol}$ for eq 1 . Very similar results of $\mathrm{SD}=2.09$ $\mathrm{kJ} / \mathrm{mol}, \mathrm{AAE}=1.52 \mathrm{~kJ} / \mathrm{mol}$, and $\mathrm{AE}=0.061 \mathrm{~kJ} / \mathrm{mol}$ were found for eq 2 . There is therefore very little bias in the predictions using eq 1 (coefficients in Table $2 \mathrm{~S}$ ) with $\mathrm{AE}=$ $0.075 \mathrm{~kJ} / \mathrm{mol}$ and eq 2 (coefficients in Table $3 \mathrm{~S}$ ) with $\mathrm{AE}=$ $0.061 \mathrm{~kJ} / \mathrm{mol}$.

The list of ion-specific equation coefficients that we have provided in Tables 2 and 3 can be easily updated or increased to include more cations/anions as experimental data for more RTILs becomes available. Should one wish to calculate additional ion-specific equation coefficients for the Abraham model there are calculation methods that can be used that would not significantly change the values that have already been calculated. One simple method would be to redefine the regressed "dependent experimental value" as

$$
\begin{array}{r}
\text { regressed value }=\Delta H_{\text {solv }}-c_{\text {ion }}-e_{\text {ion }} E-s_{\text {ion }} S-a_{\text {ion }} A- \\
b_{\text {ion }} B-v_{\text {ion }} V
\end{array}
$$

regressed value $=\Delta H_{\text {solv }}-c_{\text {ion }}-e_{\text {ion }} E-s_{\text {ion }} S-a_{\text {ion }} A-$

$$
b_{\text {ion }} B-v_{\text {ion }} L
$$

the difference between the experimental $\Delta H_{\text {solv }}$ value and the calculated contribution for the ion whose equation coefficients are known. Equation coefficients of the other counterion could then be computed by regression analysis without altering the values that have already been determined. The computation method allows one to combine experimental data for several RTILs having the desired ion whose equation coefficients one wishes to calculate. By combining data sets, one can calculate equation coefficients for ions that otherwise might not be possible. For example, suppose that one had experimental enthalpy of solvation data for 18 different solutes dissolved in 1-methyl-3-butylammonium tosylate and enthalpy data for another set of 18 solutes dissolved in 4-methyl- $N$-butylpyridinium tosylate. There is not sufficient experimental data for either RTIL to develop a meaningful correlation model; however, when the two data sets are combined there are 36 total measured values. Alternatively, one might measure sufficient experimental enthalpy of solvation data for a given RTIL to determine a RTIL-specific correlation based on the Abraham model. In such instances, one could calculate the equation coefficients, for example for a new anion, simply by subtracting the respective cation-specific values that were determined previously from the calculated equation coefficients for the entire RTIL (i.e., $c_{\text {anion }}=c_{\mathrm{RTIL}}-c_{\text {cation }} ; e_{\text {anion }}=e_{\mathrm{RTIL}}-e_{\text {cation }}$; etc.). Both computational approaches would ensure that the Abraham model ion-specific equation coefficients that might be reported in future years for RTILs would be compatible with earlier values. The suggested computation methodology also allows one to revise the ion-specific equation coefficients for the cations $(\mathrm{BMPyr})^{+},\left(\mathrm{E}_{3} \mathrm{~S}\right)^{+},\left(\mathrm{M}_{2} \mathrm{EIm}\right)^{+}$, and $(\mathrm{BMPy})^{+}$and/or anions $(\mathrm{SCN})^{-}$and $\left(\mathrm{AcF}_{3}\right)^{-}$that were computed from limited experimental data. The ability to compute (or revise) equation coefficients of a given ion without affecting the numerical values that have been calculated for other ions is highly desirable. The popularity of RTILs as solvent media continues to grow, and new ionic liquids continue to be synthesized in response to the growing industrial demand for these rather novel liquid organic compounds.

Supporting Information Available: Table of experimental enthalpies of solvation of organic solutes in room-temperature ionic liquids, along with the solute descriptors for all of the compounds considered in the present study, and references for the experimental enthalpy of solvation data. This material is available free of charge via the Internet at http://pubs.acs.org.

\section{Literature Cited}

(1) Xie, L.-L.; Favre-Reguillon, A.; Pellet-Rostaing, S.; Wang, X.-X.; $\mathrm{Fu}, \mathrm{X}$.; Estager, J.; Vrinat, M.; Lemaire, M. Selective extraction and identification of neutral nitrogen compounds contained in straight-run diesel feed using chloride based ionic liquid. Ind. Eng. Chem. Res. 2008, 47, 88018807.

(2) Chu, X.; Hu, Y.; Li, J.; Liang, Q.; Liu, Y.; Zhang, X.; Peng, X.; Yue, W. Desulfurization of diesel fuel by extraction with [BF4]-based ionic liquids. Chin. J. Chem. Eng. 2008, 16, 881-884.

(3) Gao, H.; Xing, J.; Li, Y.; Li, W.; Liu, Q.; Liu, H. Desulfurization of diesel fuel by extraction with Lewis-acidic ionic liquid. Sep. Sci. Technol. 2009, 44, 971-982.

(4) Arce, A.; Earle, M. J.; Rodriguez, H.; Seddon, K. R.; Soto, A. Bis $\{$ (trifluoromethyl)-sulfonyl $\}$ amide ionic liquids as solvents for the extraction of aromatic hydrocarbons from their mixtures with alkanes: Effect of the nature of the cation. Green Chem. 2009, 11, 365-372.

(5) Pletnev, I. V.; Smirnova, S. V.; Egorov, V. M. Liquid-liquid extraction of organic compounds. In Ionic Liquids in Chemical Analysis; Koel, M., Ed.; CRC Press: Boca Raton, FL, 2009; pp 243-267.

(6) Xie, L.-L.; Favre-Reguillon, A.; Wang, X.-X.; Fu, X.; Vrinat, M.; Lemaire, M. Selective extraction of neutral nitrogen-containing compounds from straight-run diesel feed using polymer-supported ionic liquid moieties. Ind. Eng. Chem. Res. 2009, 48, 3973-3977.

(7) Kumar, A. A. P.; Banerjee, T. Thiophene separation with ionic liquids for desulphurization: A quantum chemical approach. Fluid Phase Equilib. 2009, 278, 1-8.

(8) Sprunger, L.; Clark, M.; Acree, W. E., Jr.; Abraham, M. H. Characterization of room-temperature ionic liquids by the Abraham model with cation-specific and anion-specific equation coefficients. J. Chem. Inf. Model. 2007, 47, 1123-1129.

(9) Sprunger, L. M.; Proctor, A.; Acree, W. E., Jr.; Abraham, M. H. LFER correlations for room temperature ionic liquids: Separation of equation coefficients into individual cation-specific and anion-specific contributions. Fluid Phase Equilib. 2008, 265, 104-111.

(10) Sprunger, L. M.; Gibbs, J.; Proctor, A.; Acree, W. E., Jr.; Abraham, M. H.; Meng, Y.; Yao, C.; Anderson, J. L. Linear free energy relationship correlations for room temperature ionic liquids: Revised cation-specific and anion-specific equation coefficients for predictive applications covering a much larger area of chemical space. Ind. Eng. Chem. Res. 2009, 8, 41454154.

(11) Proctor, A.; Sprunger, L. M.; Acree, W. E., Jr.; Abraham, M. H. LFER correlations for the solubilising characterisation of room temperature ionic liquids containing trifluoromethanesulfonate and trifluoroacetate anions. Phys. Chem. Liq. 2008, 46, 631-642.

(12) Revelli, A.-L.; Sprunger, L. M.; Gibbs, J.; Acree, W. E.; Baker, G. A.; Mutelet, F. Activity coefficients at infinite dilution of organic compounds in trihexyl(tetradecyl)phosphonium bis(trifluoromethylsulfonyl)imide using inverse gas chromatography. J. Chem. Eng. Data 2009, 54, 977-985.

(13) Sprunger, L. M.; Acree, W. E., Jr.; Abraham, M. H. Linear free energy relationship (LFER) correlations for the solubilizing characterization of room temperature ionic liquids containing triethylsulphonium and 1-butyl1-methylpyrrolidinium cations. Phys. Chem. Liq., in press.

(14) Chickos, J. S.; Acree, W. E., Jr. Enthalpies of vaporization of organic and organometallic compounds, 1880-2002. J. Phys. Chem. Ref. Data 2003, 32, 519-878.

(15) Abraham, M. H.; McGowan, J. C. The use of characteristic volumes to measure cavity terms in reversed phase liquid chromatography. Chromatographia 1987, 23, 243-246.

(16) Ge, M.-L.; Wu, J.-S.; Wang, M.-H.; Wang, L.-S. Activity coefficients at infinite dilution of polar solutes in 1-propyl-2,3-dimethylimidazolium tetrafluoroborate using gas-liquid chromatography. J. Chem. Eng. Data 2008, 53, 871-873.

(17) Wang, M.-H.; Wu, J.-S.; Wang, L.-S.; Li, M.-Y. Activity coefficients at infinite dilution of alkanes, alkenes, and alkylbenzenes in 1-propyl2,3-dimethylimidazolium tetrafluoroborate using gas-liquid chromatography. J. Chem. Eng. Data 2007, 52, 1488-1491.

Received for review May 15, 2009 Revised manuscript received July 10, 2009 Accepted July 20, 2009

IE900788P 